\title{
Revistas del Journal Citation \\ Reports sobre Comunicación
}

\section{Komunikazioari buruzko aldizkariak}

\author{
Communication Journals \\ in the Journal Citation Reports
}

\section{Ana Mendieta Bartolomé1}

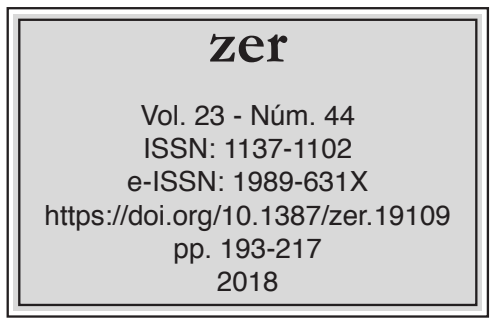

El informe del Journal Citation Reports (JCR) dedicado a las Ciencias Sociales y correspondiente a 2016 incluye 74 revistas especializadas. El criterio para diseñar el posicionamiento de estas 74 revistas ha sido el factor de impacto, que mide la repercusión que ha obtenido cada una de ellas en el campo de la comunicación. Para calcularlo, se divide el número de veces que han sido citados los artículos de cada revista en un determinado período, por el número total de artículos publicados en cada una de ellas en el mismo período.

Las tres primeras revistas con mayor factor de impacto en 2015 se han mantenido en 2016, aunque en el primer lugar en 2016 está New Media \& Society, y en el segundo lugar está Journal of Computer-Mediated Communication. La revista Journal of Communication se mantiene en el tercer lugar tanto en 2015 como en 2016.

Sin embargo, es necesario reseñar que se han producido cambios, algunos significativos, entre la clasificación del 2015 y la del 2016 que nos ocupa. Por un lado, han desaparecido cinco revistas de la clasificación del 2016, por lo que el número de revistas incluidas en el JCR ha bajado de 79 a 74 . Las cinco revistas que ya no aparecen son International Journal of Mobile Communications, que estaba en el puesto 47; Journal of Applied Communication Research, en el puesto 53; Text \& Talk, en el puesto 59; Journal of Media Economics, en el puesto 60; y Rhetoric Society Quarterly, en el puesto 62. Tres de ellas se editan en Inglaterra, una en Alemania, y una en Estados Unidos.

Por otro lado, ha habido seis revistas que han ascendido de forma ostensible entre 2015 y 2016. La revista que ha subido más escalones ha sido Journal of Advertising Research, del puesto 38 al 15. Le siguen las revistas Journal of Public Relations

\footnotetext{
Universidad del País Vasco/Euskal Herriko Unibertsitatea, anamaria.mendieta@ehu.eus
} 
Research, del puesto 40 al 20; Journalism Studies, del puesto 35 al 16; International Journal of Advertising, del puesto 30 al 11; Media Psychology, del puesto 22 al 4; e IEEE Transactions on Professional Communication, del puesto 28 al 13. Con este ascenso, Media Psychology se sitúa entre las cuatro primeras revistas de mayor factor de impacto en 2016. La única revista española en el JCR, Comunicar, también ha escalado siete posiciones, de la 19 a la 12 .

Asimismo, las caídas en el factor de impacto han sido considerables en el caso de Written Communication, que desciende 22 posiciones, de la 7 a la 39; Human Communication Research, que baja del puesto 5 al 22, International Journal of PressPolitics, del puesto 10 al 24, y Journal of Health Communication, del puesto 9 al 21 .

Las investigaciones recogidas en las 74 revistas que se incluyen a continuación abarcan un amplio abanico, tanto de tipologías clasificadas dentro del campo de la comunicación, como de temas tratados en cada una de ellas. Las tipologías de las revistas van desde la comunicación propiamente dicha, el periodismo, la publicidad, las relaciones públicas, la comunicación política, la argumentación, la psicología y las publicaciones dirigidas a una nacionalidad o un grupo étnico; hasta las revistas de salud, medioambiente, ciencia, ingeniería y telecomunicaciones. Entre los temas abordados abundan las investigaciones cuantitativas y cualitativas sobre redes sociales, contenidos digitales y nuevas tecnologías en general, pero también temas más tradicionales como el análisis del discurso o la cobertura informativa de campañas electorales

\section{New Media \& Society (Inglaterra, SAGE) Volumen 20 (5) 2018}

Los artículos incluidos en este número abordan la influencia de Facebook en el mundo del periodismo tras el cambio de algoritmo que da prioridad a los vídeos directamente subidos a esta red social, la representación de la masculinidad promovida por los bloggers de juegos en YouTube, la intersubjetividad y la representación semiótica de los selfies, y la comparación de las expresiones de emoción en Facebook, Twitter, Instagram y WhatsApp. La revista también divulga trabajos sobre la creación de comunidades transexuales online, la relación entre las rupturas sentimentales y las ideologías mediáticas en Facebook, la influencia de las redes sociales en las carreras de músicos indie, un análisis del big data sobre el poder de la agenda mediática de las noticias falsas, y el florecimiento del racismo en espacios participativos políticamente incorrectos.

2. Journal of Computer Mediated Communication (EE.UU., Wiley-Blackwell Publishing) Volumen 23 (3) 2018

La revista publica en este número tres artículos originales. El primero trata sobre las estrategias de presentación y estilos lingüísticos en Facebook. El segundo trabajo presenta la influencia de los mensajes de Twitter en la predisposición de los internautas a ayudar a las víctimas de ciberacoso. El tercer artículo explica la gestión de las imágenes en redes sociales en base a nociones de respetabilidad por parte de los jóvenes pertenecientes a una clase socioeconómica ascendente en Nueva York. 


\section{Journal of Communication (EE.UU., Wiley-Blackwell) Volumen 68 (2) 2018}

La revista celebra sus 35 años de vida con un número especial que reflexiona sobre el futuro de los estudios de comunicación en el ámbito mediático digital actual. Las investigaciones incluidas se centran en un nuevo marco para comprender los conceptos de origen étnico e interacción intergrupal, la infrarrepresentación de los académicos de minorías étnicas en las publicaciones de ciencias sociales, y el impacto de las tecnologías digitales en el flujo y la democratización de la información. Otros trabajos estudian la influencia del neocapitalismo liberal en las subjetividades y desigualdades de género, la importancia de la orientación postcolonial y de la ética en los estudios de comunicación, y la coexistencia de las teorías críticas y empíricas en la investigación social.

\section{Media Psychology (EE.UU., Taylor \& Francis) Volumen 21 (2) 2018}

El ejemplar de esta revista contiene textos sobre la influencia del número de "Likes" y las actualizaciones de estado en el feedback que reciben los usuarios de redes sociales, la importancia de las imágenes en el consumo mediático desde las redes sociales, los efectos emocionales de los mensajes de Instagram, los apoyos mutuos creados entre los jugadores de videojuegos, y en particular de Pokémon Go como catalizador de experiencias de vida positivas, y la importancia de la persistencia en los sistemas de comunicación informática.

\section{Communication Research (EE.UU., SAGE) Volumen 45 (3) 2018}

Este número se dedica al examen de las relaciones románticas en diversas facetas académicas. Entre estas facetas podemos encontrar un modelo de gestión de las relaciones derivadas de la transición a la familia extendida tras el matrimonio, un estudio de la asociación entre el orgasmo, la comunicación y la satisfacción en la relación de pareja, los déficits y beneficios de la terapia de pareja en el procesamiento de los factores de estrés marital, y la resolución constructiva del conflicto a través de la interacción variable en las relaciones románticas entre adultos. Asimismo, las investigaciones plasmadas en el ejemplar estudian la efectividad de la teoría de la información motivada para manejar la inseguridad financiera en parejas estables, la importancia del retrato mediático del romanticismo en el refuerzo de las actitudes proclives al acoso sexual, y los efectos positivos de la conversación en pareja para predecir resultados psicológicos y emocionales.

\section{Journal of Advertising (EE.UU., Taylor \& Francis) Volumen 47 (2) 2018}

Este número incluye investigaciones sobre el impacto de la sensibilidad olfativa en los anuncios que apelan a este sentido, la influencia de los donantes en las campañas publicitarias de recaudación de fondos para enfermedades menos controlables 
por los afectados, las consecuencias de la publicidad engañosa en la percepción de los consumidores sobre productos que protegen el medioambiente, la relación de la individualidad y el colectivismo en los mensajes sobre la importancia del ahorro familiar, la publicidad orientada a parejas del mismo sexo, y el efecto de la distancia psicológica en la respuesta de los consumidores a los tabús de sexo y violencia en la publicidad.

\section{Communication Theory (EE.UU., Wiley-Blackwell) Volumen 28 (1) 2018}

Las investigaciones que comprende la presente edición abordan el valor de las preguntas en la generación de bienes de información pública online, la construcción de la presencia social del comunicador en un ambiente multicomunicativo digital, el uso de las redes semánticas en la comunicación de la persuasión, las teorías de la psicosis aplicadas a las redes sociales, y un enfoque comparativo en la historia de las tecnologías comunicativas.

8. Information, Communication \& Society (Inglaterra, Taylor \& Francis) Volumen $21(8) 2018$

Diferentes aspectos relacionados con las redes sociales y las aplicaciones móviles centran la atención de este ejemplar. Los temas estudiados abarcan el uso de Facebook y Twitter por los políticos alemanes en las elecciones federales de 2013, las aplicaciones anti-violación, la desconfianza creada por los usuarios de redes sociales que borran sus propios contenidos, y el disfrazamiento de la identidad por parte de colaboradores de páginas web. También se estudia la utilización de hashtags en Twitter por parte de periodistas y políticos, la influencia de la identidad grupal y racial en el uso de Twitter por la comunidad afroamericana en Estados Unidos, el ciberactivismo como medio de conexión y contranarrativa del colectivo de discapacitados, los predictores de sobrecarga de información en las noticias online, y las estrategias de los adolescentes para detectar la edad de los usuarios de redes sociales.

\section{Public Understanding of Science (Inglaterra, SAGE) Volumen 27 (4) 2018}

Este ejemplar dispone de un monográfico sobre el Premio Nobel y la imagen pública de la ciencia y de los científicos. Los artículos de este especial abordan el interés suscitado por la ciencia en la opinión pública tras la concesión de los Premios Nobel. Pero los textos se centran sobre todo en la imagen de los laureados como símbolos de excelencia, tanto en sus discursos de recogida del premio, como en su imagen mediática de genios y celebridades en la revista Scientific American, de ciudadanos comprometidos y héroes solitarios en la televisión británica, y en su representación en el cine y la televisión desde la película La fin du monde hasta la serie The Big Bang Theory. 
10. Political Communication (Inglaterra, Taylor \& Francis) Volumen 35 (2) 2018

El impacto electoral de la comunicación política en las redes sociales es el principal objeto de estudio en este ejemplar. El lector tiene a su disposición investigaciones acerca del rol de Facebook, Twitter, Microsoft y Google en la comunicación política de las campañas electorales de Estados Unidos en 2016; la conexión del estatus socioeconómico familiar con la comunicación política difundida en el hogar, y el consecuente interés de los hijos por los procesos electorales vigentes; la tendencia de los difusores de rumores en Twitter a aceptar correcciones en base a informaciones veraces procedentes de verificadores de datos; y el estudio de la opinión pública favorable a las historias personales que cuentan los candidatos políticos en las convenciones de sus partidos. También hay estudios sobre las mayores audiencias televisivas por las noticias sensacionalistas en detrimento de las noticias de interés público, el impacto de los medios en las preferencias de los votantes durante el transcurso de una campaña electoral, la influencia de la opinión pública creada en Twitter en la evaluación de los políticos en debates televisados en Corea del Sur, y el papel de las élites conservadoras en el escepticismo ideológico de sus bases respecto al cambio climático y a la teoría de la evolución humana.

11. International Journal of Advertising (Inglaterra, Advertising Association) Volumen 37 (3) 2018

Esta revista de comunicación publicitaria plantea en el editorial de su último número "una alerta roja" sobre la necesidad de más investigación acerca de la responsabilidad social corporativa en la publicidad. Además, este número publica artículos sobre el impacto de la emoción del texto publicitario en la utilidad de las reseñas de productos online, la influencia del boca a boca en las redes sociales, el efecto de los estilos de vida en el uso de aplicaciones móviles, la autopercepción y el narcisismo de los consumidores en su reacción a la publicidad, el rol de la humanización en los anuncios, y los resultados de los anuncios de nutrición en las revistas femeninas.

\section{Comunicar (España, Grupo Comunicar) Volumen 26 (55) 2018}

Los lectores del presente número de la revista disponen de investigaciones sobre el perfil académico de los periodistas científicos en España, un análisis de los relatos periodísticos sobre la violencia contra la mujer en Brasil en 2013 y 2014, la incidencia política de las campañas contra la trata de personas con fines de explotación sexual en España de 2008 a 2017, y la articulación de la opinión pública en Twitter durante la visita a México del entonces candidato presidencial Donald Trump en 2016. Asimismo, otros temas tratados son el reflejo en Twitter de la disolución del Consejo de la Juventud de España (CJE) y el impacto de los jóvenes en la esfera pública (2012-2014); los youtubers y la construcción de la identidad adolescente en España; un análisis de las dos teorías enfrentadas respecto a la noción de los 
consumidores, prosumidores y emirecs; un mapeo científico de la Categoría "Comunicación" en la Web of Science (1980-2013); el uso de la gamificación transmedia en el denominado Aprendizaje Digital Basado en Juegos para la divulgación científica; el fomento de vocaciones procientíficas en adolescentes; y una revisión del estado de la literatura científica sobre el concepto MOOC y sus distintas tipologías, como los tMOOC (Cursos Online Abiertos de Transferencia Masiva).

13. IEEE Transactions on Professional Communication (EE.UU., IEEE-The Institute of Electrical and Electronic Engineers, Inc.) Volumen 61 (1) 2018

En esta revista sobre ingeniería eléctrica y electrónica se pueden consultar estudios sobre la comunicación entre agencias gubernamentales y comunidades locales en situaciones de riesgo medioambiental, el discurso de tres empresas con intereses en la herencia cultural de la gran muralla Mutianyu al norte de Pekín, la instrucción de la función persuasiva en los currículums de los estudiantes de ingeniería, las diferencias retóricas entre los artículos de alto y bajo impacto en el campo de la ingeniería química, la gestión del contenido multilingüe de calidad en empresas de carácter global, y las estrategias de aprendizaje comunicativo de los estudiantes de Sistemas de la Información en Taiwán.

14. Technical Communication (EE.UU., Society for Technical Communication) Volumen 65 (2) 2018

Esta publicación de cariz especializado publica trabajos sobre diferentes tipos de iniciativas empresariales, como proyectos de gestión flexible en organizaciones dedicadas al comercio, proyectos de comunicación empresarial llevados a cabo por ingenieros recién licenciados, proyectos de gestión del lenguaje en equipos de máximo rendimiento, iniciativas de gestión de centros de salud comunitarios, y planes emergentes de comunicación técnica.

\section{Journal of Advertising Research (EE.UU., Advertising Research Foundation) Volumen 58 (1) 2018}

Este ejemplar dedica sus artículos a las campañas publicitarias patrocinadas por celebridades y a la necesidad de mantener vivo el conocimiento empírico en la investigación publicitaria. Las investigaciones sobre celebridades tratan la influencia de su apoyo a campañas publicitarias de aerolíneas y del mercado de valores en economías emergentes como la de India, y su efecto como valor añadido a la confianza del consumidor en ese producto y en su actitud hacia la compra. Otros estudios examinan el efecto de los medios digitales de pago en la venta de marcas, la actitud de los consumidores chinos hacia marcas que se publicitan dentro y fuera de Internet, y el impacto de la teoría de la retórica en el proceso creativo de la publicidad. 


\section{Journalism Studies (Inglaterra, Taylor \& Francis) Volumen 18 (8) 2018}

El último ejemplar de esta revista británica analiza la cobertura periodística mundial en una variada gama de temas. Entre estos temas destacan la representación positiva del Islam en la cobertura de la prensa estadounidense de las relaciones entre Estados Unidos y Arabia Saudí durante la guerra fría, las noticias en la prensa británica sobre los soldados de este país posando con cadáveres en la guerra de Afganistán, la relación entre las decisiones informativas y la medición de la popularidad de las noticias online, y la cobertura de África en los medios occidentales en base a mitos de oscuridad y tribalismo. El resto de artículos aborda el discurso en la prensa británica de la filosofía del "Buen Vivir" y del socialismo del siglo XXI, presente en las elecciones presidenciales de Bolivia, Ecuador y Venezuela en 2013 y 2014; la conexión entre los valores y tópicos presentes en las noticias online de Estados Unidos, Brasil y Argentina con la interacción de la audiencia en las redes sociales; los cambios en la cobertura de la violencia de género en Australia; y la influencia económica y también mediática de China en el periodismo local de Sudáfrica.

\section{Research on Language and Social Interaction (EE.UU., Taylor \& Francis) Vo-} lumen 51 (1) 2018

La presente edición de esta revista divulga trabajos que giran alrededor de la relación de las estructuras gramaticales con la actitud corporal, la lingüística interactiva, y el análisis de la conversación; la influencia de los movimientos corporales en las opciones gramaticales; el estudio de las evaluaciones gramaticales basadas en la lógica deóntica de las ideas normativas; los efectos fonéticos de las quejas infantiles en las interacciones familiares; el uso del imperativo en comparación a las sesiones de un combate de boxeo; y los retos de la transcripción de grabaciones de vídeo en francés y alemán por la diversidad de prácticas multimodales corporales y lingüísticas.

\section{Science Communication (EE.UU., SAGE) Volumen 40 (2) 2018}

Esta publicación cuenta con estudios acerca de la relación entre el conocimiento científico y una predisposición favorable a la ciencia en la opinión pública de Corea del Sur; el efecto de los encuadres de conocimiento competitivos o complementarios en las actitudes de la opinión pública a favor del medioambiente y de las tecnologías verdes, el análisis de las imágenes que suscitan el compromiso del consumidor con la gestión sostenible del agua en las ciudades, la percepción de la ciencia como bien público en las manifestaciones contra la política científica de la administración Trump en Estados Unidos, la importancia del audio en la disponibilidad online de las comunicaciones científicas, la polarización política en la información sobre el cambio climático, y el fomento de interés en la química entre los jóvenes ingleses a través de demostraciones con artesanía textil. 
19. Communication Monographs (Inglaterra, Taylor \& Francis) Volumen 85 (2) 2018

Los lectores de este último número pueden acceder a investigaciones que abordan el análisis de los patrones de comunicación familiar a partir de una escala de conformidad expandida; la gestión por parte de las parejas adultas casadas de la discriminación percibida en el tratamiento de los riesgos de enfermedades genéticas; el uso de los chats como herramienta de apoyo emocional; la intersección de marcadores identitarios como el género, el origen étnico y socioeconómico y las emociones en la gestión de la fuerza laboral en organizaciones burocráticas como ayuntamientos y aeropuertos; el tratamiento del estrés causado por los retos lingüísticos que enfrentan los adolescentes latinos en Estados Unidos; y la construcción de los discursos identitarios de los trabajadores noruegos ante la nueva situación política y económica del país.

20. Journal of Public Relations Research (EE.UU., Taylor \& Francis) Volumen 29 (6) 2017

El editorial de este número presenta una reflexión sobre los riesgos de la predominancia del inglés y del modelo estadounidense en la práctica de las relaciones públicas. Los artículos incluidos se centran en el establecimiento de un marco conceptual para entender la relación entre los constructos económicos, políticos y mediáticos y la práctica de las relaciones públicas en Singapur; la influencia del historial positivo de una empresa con la percepción pública de su gestión de la crisis alimentaria en Corea del Sur; y las estrategias en el desarrollo y cuidado de las relaciones públicas en la diplomacia de Estados Unidos.

21. Journal of Health Communication (EE.UU., Taylor \& Francis) Volumen 23 (4) 2018

Los artículos de este número recogen el uso de la entrevista para aumentar la motivación de los padres a dar la vacuna del papiloma humano a sus hijas adolescentes; la aplicación de la sensibilidad cultural en la información sobre programas de prevención de salud bucal y contra el tabaquismo dirigidos a los latinos hispanoparlantes en Estados Unidos, así como en el cuidado oncológico de pacientes homosexuales, bisexuales y transexuales. Las investigaciones también analizan la efectividad de los programas informativos de salud entre las mujeres inmigrantes en Taiwán, el retrato positivo de los cigarrillos electrónicos de marihuana en YouTube, la conjunción del uso de la vareniclina con mensajes de texto en teléfonos móviles en el tratamiento del tabaquismo, el uso de mensajes de texto para monitorizar el cumplimiento del ejercicio y la dieta entre los usuarios de las aplicaciones de fitness, la influencia de la promoción de menús saludables en la publicidad de restaurantes de comida rápida, y la importancia de los 'likes' dados por expertos en la credibilidad de la información sobre salud difundida en Facebook. 
22. Human Communication Research (EE.UU., Wiley-Blackwell) Volumen 44 (2) 2018

Los temas de este ejemplar giran alrededor de las funciones persuasivas de los mensajes multi-emotivos, el cambio en las relaciones afectivas tras un conflicto como extensión de la teoría de las implicaciones identitarias, el estudio de los encuadres comunicativos para mejorar el procesamiento de la información política, la influencia de la experiencia personal en las percepciones de la opinión pública, y una aproximación a la teoría del activismo de salón (Slacktivism en inglés) y su relación con la participación política en las redes sociales.

\section{Telecommunications Policy (Inglaterra, Elsevier) Volumen 42 (4) 2018}

Este ejemplar se enfoca en el Big Data y el Internet de las Cosas, por lo que los artículos ofrecen investigaciones sobre la necesidad de un marco regulatorio de los especuladores que venden datos personales sin el consentimiento de los usuarios; el Internet de las Cosas como acelerador de las redes de banda ancha en Tailandia y como aplicación para la gestión de los sistemas de salud; el uso de mecanismos para incentivar el uso compartido del espectro de banda ancha; la implementación de un nuevo servicio de salud nacional en Vietnam; y los retos socioeconómicos de la desigualdad en una sociedad hiperconectada.

24. International Journal of Press/Politics (EE.UU., SAGE) Volumen 23 (1) 2018

Los seis trabajos incluídos en esta edición difunden temas relacionados con el rol de la prensa en la información política. Entre los temas tratados hay un estudio longitudinal y comparativo de la confianza del público en la prensa a nivel mundial, una comparación de la función democratizante que ejercen la prensa escrita y la televisión en Chile, el activismo de los periodistas en los movimientos por la justicia social en Israel en 2011, el impacto electoral de la representación de los líderes de los partidos políticos en Holanda, los efectos polarizantes entre demócratas y republicanos en Estados Unidos creados por las disputas online entre los partidos políticos, y, por último, un análisis de la credibilidad de las noticias en Ucrania más basada en las prioridades de los lectores que en los hechos informativos.

\section{International Journal of Communication (EE.UU., USC Annenberg Press) Vo-} lumen 12,2018

El último número de esta revista contiene artículos de investigación y secciones especiales. Los artículos abordan los flujos de información regional y global en el buscador Google Trends, la influencia de los medios chinos en Kenia y Sudáfrica, el impacto de las tecnologías de la información en la movilización política de la África subsahariana, la revisión de un marco teórico para la tipología del populismo desde 
el lado del emisor y del receptor, el uso de los activistas sudafricanos de los nanomedios y los medios digitales, la percepción de los periodistas de televisión sobre las presiones organizativas en los contenidos, y la dependencia de las noticias online respecto del contenido suministrado por las agencias de noticias. Por otro lado, otros trabajos divulgan el efecto positivo en la ciudadanía de las reacciones en Twitter del presidente Trump ante las parodias que recibe en el programa Saturday Night Live; el papel de Twitter en el flujo comunicativo entre partidos políticos en el parlamento catalán, y en la construcción de la memoria histórica en China; el estudio en tiempo real de las respuestas de la audiencia a los mensajes políticos; y las consecuencias de la exposición de los ciudadanos a los medios y su percepción de la desigualdad social en Colombia. La sección de temas especiales se centra en el impacto de los medios en la esfera emocional; con estudios de caso sobre la cobertura de la crisis financiera europea en los medios del Reino Unido, y la actitud hacia las emociones de los periodistas digitales españoles. La última parte de esta sección contiene cinco investigaciones sobre el problema de las actitudes incívicas en la comunicación digital en China.

\section{Health Communication (EE.UU., Taylor \& Francis) Volumen 33 (7) 2018}

Tres de los artículos incluidos en esta edición difunden trabajos en relación al alcohol y al tabaco. Dos artículos analizan la postura neutral o negativa de los editoriales de prensa respecto al control del tabaquismo y al establecimiento de espacios libres de tabaco, así como la influencia de la distancia social y emocional en las respuestas de los no fumadores a los mensajes contra el tabaquismo. El tercer artículo aborda los mensajes de prevención, para controlar el abuso del alcohol entre estudiantes universitarios, con hincapié en las iniciativas que combinan la educación con el entretenimiento. El resto de trabajos trata el efecto de las imágenes mediáticas en las mujeres embarazadas y de postparto, la integración de los sistemas sanitarios en el tratamiento del cáncer en Suecia, las encuestas sobre la ley de cobertura sanitaria del presidente Obama entre 2010 y 2016, un estudio de la escritura creativa para paliar la carga emocional y el estrés de los cuidadores de enfermos de cáncer, la importancia de las donaciones de tejido mamario sano para la investigación del cáncer de mama, la relevancia de los factores sociodemográficos en la relación entre médico y paciente, y las barreras comunicativas existentes en las consultas pediátricas de salud mental.

\section{Journalism (EE.UU., SAGE) Volumen 19 (5) 2018}

Este ejemplar contiene un especial sobre el consumo, la confianza en los medios, y el compromiso ciudadano. Los temas abordados estudian la perspectiva de los propios ciudadanos suecos respecto a su participación en los medios de su país, la credibilidad de los lectores hacia las noticias generadas por ordenadores, la confianza en el periodismo ciudadano como creador de una mayor participación online, las diferentes etapas del consumo mediático entre estudiantes universitarios, y el periodismo 
de soluciones en comunidades estigmatizadas por la pobreza y la violencia en Los Angeles. También hay trabajos sobre el significado del click del usuario en la selección y exploración digital de las noticias; la correspondencia entre la experiencia de una noticia en primera persona y la confianza de los ciudadanos hacia los periodistas en Israel; la relación entre la actividad en redes sociales y el interés informativo entre los jóvenes milenials (los nacidos entre 1982 y 2004) en Holanda; y el declive del interés por la información política, pero no por la información en general, entre los usuarios de redes sociales y teléfonos móviles en Estados Unidos.

28. Journal of Social and Personal Relationships (Inglaterra, SAGE) Volumen 35 (5) 2018

La presente edición de esta revista dedica sus artículos al papel que juega el contexto de una relación romántica en la pérdida de peso de un miembro de la pareja, la gestión online del estrés de la vida militar por parte de los padres de soldados en servicio activo, la relación entre la satisfacción y la disposición de sacrificio en la pareja, la conexión entre la estabilidad familiar y el rendimiento académico y emocional de los estudiantes universitarios, y un análisis del nivel de estrés y satisfacción en las relaciones de adolescentes en Suiza.

29. Environmental Communication (Inglaterra, Taylor \& Francis) Volumen 12 (4) 2018

Los lectores interesados en temas del entorno y los ecosistemas disponen en este número de investigaciones sobre la importancia de la experiencia ecológica en la reevaluación de la comunicación medioambiental, los debates legislativos sobre la reforma de la política acuífera en Irlanda, el uso de Internet por las organizaciones ecologistas que luchan contra el cambio climático en Estados Unidos, y el análisis de la comunicación en las luchas de poder indígena en la Amazonía peruana. Otros textos abordan la importancia de la visualización y del arte para atraer la atención ciudadana sobre riesgos medioambientales como la contaminación, el discurso sobre el cambio climático en los periódicos griegos, la integración de sistemas de información geográfica y técnicas ecolingüísticas para el debate sobre las minas de cobre en Arizona, las campañas de comunicación sobre la sequía y la conservación del agua en California, y el cambio ejercido por las ONG globales en la cobertura de la prensa japonesa de las negociaciones sobre el cambio climático.

30. European Journal of Communication (Inglaterra, SAGE) Volumen 33 (2) 2018

En este último número se pueden encontrar artículos que exploran el tema de la post-verdad en la política y en la comunicación pública. Estos artículos abordan la desinformación, el declive de las instituciones democráticas, los ajustes en el periodismo tras las campañas del Brexit y de Donald Trump, el principio de la intersubjetividad frente al de la objetividad engañosa en la comunicación política, y 
las protestas políticas con testimonios personales de los manifestantes en forma de memes de Internet. El discurso de las tertulias políticas de la televisión griega en las horas de máxima audiencia, las implicaciones de imparcialidad y post-verdad en los programas de sátira y periodismo en la televisión británica y la estadounidense, y la post-verdad en las redes sociales son los temas del resto de los artículos.

\section{Public Opinion Quarterly (Inglaterra, Oxford University Press) Volumen 82} (S1) 2018

El monográfico de este número está centrado en la utilización de la psicología para comprender los procesos electorales. En concreto, los artículos incluidos examinan la interacción entre las emociones y el sexismo, así como entre la personalidad y las actitudes políticas de los votantes en las elecciones presidenciales estadounidenses de 2016; la polarización existente entre la identidad ideológica y las posturas hacia los temas de actualidad del electorado estadounidense; las predicciones electorales de la prensa partidista en Estados Unidos; la medición del proceso que sigue el electorado estadounidense a la hora de elegir su voto; y su impacto en la investigación de la opinión pública.

\section{Television \& New Media (EE.UU., SAGE) Volumen 19 (4) 2018}

Este ejemplar es un monográfico centrado en el renacimiento de las series de culto de la televisión estadounidense, con hincapié en los contextos de producción y recepción, y en las prácticas textuales, culturales y corporativas. Para analizar el tema se incluyen artículos sobre el regreso de las series Twin Peaks: The Return más de dos décadas después de la serie original; The X-Files, con nuevas estrategias de storytelling adaptadas a la multipantalla; y de Arrested Development, Full House, y Gilmore Girls: A Year in the Life en Netflix. Arrested Development es la historia de una familia acaudalada arruinada con la crisis hipotecaria en Estados Unidos, Full House es la trama de tres hombres solteros padres de tres niñas, y Gilmore Girls: A Year in the Life es la continuación de las peripecias de una madre y una hija que viven en un pequeño pueblo ficticio de Estados Unidos.

33. Journal of Broadcasting \& Electronic Media (EE.UU., Taylor \& Francis) Volumen 62 (2) 2018

Este número difunde trabajos que examinan el uso de las redes sociales para aumentar las audiencias en televisión, la relación curvilínea entre el uso de Facebook y la autoestima de los jóvenes holandeses, la mediación de los hijos en el consumo televisivo de sus padres en Bélgica, la evaluación de la credibilidad de la información de salud online a través de técnicas heurísticas, y las respuestas de vulnerabilidad y resiliencia de los usuarios de los videojuegos con múltiples jugadores. También hay investigaciones sobre la persistencia de una mayor exposición de los usuarios a las 
noticias a través de la televisión, frente al teléfono móvil e Internet, en un estudio realizado en 56 países; la interacción entre personajes de diferentes orígenes étnicos y la representación corporal femenina en programas de televisión de máxima audiencia en Estados Unidos; y la influencia de la publicidad electoral en una mayor búsqueda de información política online.

\section{Public Relations Review (EE.UU., Elsevier) Volumen 44 (2) 2018}

Entre los temas incluidos en este último número de la revista destacan, por un lado, la diferente percepción del poder que tienen los profesionales de las relaciones públicas según su género; la correspondencia entre los ataques políticos y los retweets conseguidos por Donald Trump y Hillary Clinton en las elecciones presidenciales de 2016; la respuesta de las universidades con alto número de alumnado extranjero al veto migratorio de Donald Trump; y la explotación realizada por el canal de televisión estadounidense TLC del escándalo de abuso sexual cometido por Josh Duggar, actor del reality show 19 Kids and Counting. Por otro lado, este ejemplar presenta las experiencias de adversidad y resiliencia de los profesionales de las relaciones públicas en el lugar de trabajo, un análisis de la credibilidad y la gestión de la comunicación política en los procesos electorales de Estados Unidos en 2016, la percepción del público sobre la transparencia de los mensajes informativos, las estrategias de redes sociales utilizadas por los gobiernos locales en Latinoamérica para relacionarse con los ciudadanos, y un enfoque activista de las relaciones públicas como instrumento para reflejar las desigualdades de poder en la sociedad.

35. Mass Commmunication and Society (EE.UU., Taylor \& Francis) Volumen 21 (3) 2018

La presente edición divulga textos que ahondan en la psicología detrás de una visión maratoniana de la televisión, la audiencia de los contenidos mediáticos de tipo trascendente o inspirador en Estados Unidos, la influencia del carácter moral de la audiencia en la selección de la moralidad de los personajes en los contenidos de entretenimiento, el visionado de vídeos positivos en el lugar de trabajo como fuente de gratificación laboral, y la falta de diversidad de género y de origen étnico de los directores y productores estadounidenses nominados a los Oscars en la categoría documental.

36. Journalism \& Mass Communication Quarterly (EE.UU., SAGE-AEJMC) Volumen 95 (1) 2018

En esta edición se pueden encontrar investigaciones acerca de la metodología de investigación cualitativa inductiva conocida como la Teoría Fundamentada en Datos, las escalas de valoración de la verdad y de diferentes formatos y tonos para la verificación de datos en las páginas web Factcheck.org y FlackCheck.org, la credi- 
bilidad de la prensa local estadounidense, y el uso de la base de datos LexisNexis para el análisis de noticias sobre inmigración. También hay estudios sobre las listas de noticias más vistas en los medios online, el perfil de los usuarios de blogs científicos, la conexión entre el consumo informativo y la participación política de los jóvenes, el recorrido del principal periódico sufragista femenino del siglo XIX en EE.UU., la relación entre la agresividad y el consumo de reality shows en formato de documentales de la vida cotidiana o docusoaps, las diferentes jerarquías entre los periodistas especializados en finanzas, y el proceso de revisión a pares en las revistas especializadas en periodismo.

37. Journal of Language and Social Psychology (EE.UU., SAGE) Volumen 37 (3) 2018

El presente ejemplar difunde trabajos sobre el contenido emocional de los artículos de Wikipedia respecto a los desastres naturales y los causados por la humanidad, la responsabilidad moral de los radioyentes que reproducen estereotipos en sus intervenciones telefónicas, el efecto persuasivo de los comentarios en inglés y chino mandarín a los vídeos de YouTube que promueven la conservación del agua. Otras investigaciones examinan los estereotipos existentes hacia los latinos que hablan inglés con acento en Estados Unidos, la discriminación linguiística hacia la minoría gitana romaní, los factores psicológicos que determinan la pureza lingüística, y el reflejo del estatus socioeconómico en los discursos de aceptación de los ganadores de los premios Óscar.

38. International Journal of Public Opinion Research (Inglaterra, Oxford University Press) Volumen 30 (1) 2018

Los temas en los que se centra la presente edición abordan el apoyo público a la censura en países con alto control estatal de los medios como Singapur, la evolución de la opinión pública suiza sobre la energía nuclear tras el accidente de Fukushima, la influencia que pueden ejercer grupos de público controlado a un público menos informado encuestado sobre los cambios a la Seguridad Social en Estados Unidos, y la credibilidad de las redes sociales en China según la perciben sus usuarios. El resto de estudios difunde las características de la segunda ola feminista en Europa; la correlación entre las conexiones de la comunidad judía de Estados Unidos con Israel y su postura sobre el acuerdo nuclear con Irán; y la correspondencia entre la falta de civismo en el lenguaje de los políticos online y el impacto negativo que éste ejerce en la credibilidad de los medios.

\section{Written Communication (EE.UU. SAGE) Volumen 35 (2) 2018}

En esta edición el lector encontrará artículos sobre el método de enseñanza con vídeo en las clases de Lengua de estudiantes noruegos de educación secundaria, la 
escritura colaborativa en una agencia sin ánimo de lucro para defender los derechos del alumnado, la creación de un proyecto digital multimodal por el alumnado de una clase de inglés de educación secundaria, y el uso de herramientas de codificación para gestionar la complejidad del lenguaje.

\section{Media Culture \& Society (Inglaterra, SAGE) Volumen 4 (4) 2018}

Este ejemplar recoge investigaciones sobre el uso que hacen de Facebook los solicitantes de asilo que llegan a las costas de Australia para contar su propia historia, la institucionalización de los medios en el gobierno británico, la reinterpretación de la violencia extremista en el discurso mediático en Israel, la incidencia de las mujeres influidoras en los debates políticos online adoptando el rol de divas, madres, o chicas duras en un mundo sexista, las nuevas rutinas de los periodistas deportivos de Canadá en la era digital. La atención también está centrada en la economía política del riesgo que corren los periodistas en zonas de guerra; el discurso público en Twitter tras el terremoto de Nueva Zelanda de 2011; las asociaciones de mujeres periodistas en la segunda ola post-feminista en Estados Unidos; el caso de la organización The Yes Men, que se hizo pasar por defensora de la empresa Chevron en una falsa campaña publicitaria con un gran eco mediático; y el rol de las luchas políticas en las tecnologías mediáticas.

\section{Games and Culture (EE.UU., SAGE) Volumen 13 (4) 2018}

Las investigaciones que divulga este número se dirigen al reflejo del juego informático League of Legends en los comportamientos cívicos de sus jugadores, el estudio de las plataformas digitales desde un enfoque epistemológico, las teorías utópicas de la sociedad creadas por los videojuegos y los consecuentes dilemas éticos de sus jugadores, los desórdenes psicológicos entre los jugadores patológicos de apuestas en dispositivos móviles, y la utilización de un juego informático de equipamiento de cárceles virtuales para examinar la actitud de sus jugadores hacia el castigo y la reinserción.

\section{Management Communication Quarterly (EE.UU., SAGE) Volumen 32 (2) 2018}

Los trabajos de este número se enfocan en la gestión de diferentes fuentes de problemas en el entorno laboral, la promoción del liderazgo femenino, y la fuerza laboral que "ha salido del armario" por su identidad sexual, su religión, su condición migratoria, su discapacidad, o sus adicciones. Los otros artículos descubren el proceso seguido por los empleados que abandonan una empresa abusiva y dictatorial, como en el caso de la desmantelada iglesia Mars Hill en Estados Unidos; la implementación de la sostenibilidad en los recursos discursivos de las empresas; el discurso de la disculpa en la comunicación de una crisis corporativa; la construcción del liderazgo femenino en los campos de ciencia y tecnología en Singapur; el estudio de las redes de comunicación organizativa con modelos gráficos aleatorios exponenciales; 
el ejercicio de una comunicación empresarial que no discrimine la identidad queer o transexual de los empleados y sus familias; y la inclusión en las guías de comunicación corporativa empresarial de académicos afroamericanos, académicos extranjeros, y empleados ex adictos.

\section{Discourse \& Communication (Inglaterra, SAGE) Volumen 12 (3) 2018}

Este ejemplar presenta trabajos sobre la fabricación del sueño americano en la representación de los refugiados sirios en los medios estadounidenses, la construcción de un discurso online contra la comunidad romaní en el Reino Unido, la legitimación multimodal en los anuncios electorales del partido Nueva Democracia en los comicios griegos de 2015, las prácticas discursivas relacionadas con la creación de una agencia federal para administrar los hospitales universitarios en Brasil, y la comunicación entre una fundación filantrópica en Estados Unidos y los solicitantes de ayudas.

44. Journal of Business and Technical Communication (EE.UU., SAGE) Volumen 32 (3) 2018

Los temas de este número giran alrededor de la redacción de una propuesta de ingeniería medioambiental con hojas de cálculo, los programas de gestión de contenidos y su relación con la motivación laboral, el diseño de las páginas web de los Sitios del Patrimonio Mundial de la UNESCO, y la importancia de los lazos personales en las redes de colaboración científica, educativa y empresarial.

45. Journal of Media Psychology-Theories, Methods and Applications (Alemania, Hogrefe \& Huber) Volumen 30 (2) 2018

En este ejemplar los expertos analizan las consecuencias patológicas del uso de videojuegos entre los adolescentes alemanes; la correlación entre la lectura de noticias positivas sobre el país de origen y la evaluación positiva del mismo por encima de otros países, conocida como distinción positiva; la repercusión de los contenidos mediáticos relativos a la moralidad en la propia moralidad de las audiencias; el alcance de las simulaciones virtuales para conocer los riesgos de los refrescos para la salud; y la gratificación de las audiencias en el consumo de los programas de telerrealidad.

46. Ecquid Novi-African Journalism Studies (Sudáfrica, Taylor \& Francis) Volumen 39 (1) 2018

Las investigaciones en este ejemplar están enmarcadas en un monográfico sobre los medios digitales en África, y difunden el uso de los blogs como herramienta de activismo político por las mujeres de Zimbabwe, el fomento de la democracia par- 
ticipativa en las redes sociales de Ghana, las redes sociales y la seguridad nacional en Zimbabwe, la participación de los jóvenes en las elecciones de 2015 en Nigeria a través de las redes sociales, y el uso de Twitter por los periodistas del Daily Nation en Kenia.

\section{Discourse \& Society (Inglaterra, SAGE) Volumen 29 (3) 2018}

En esta edición el lector encontrará artículos sobre la construcción de una narrativa de los "hinchas violentos" tras la tragedia del estadio de fútbol de Hillsborough en 1989; dos entrevistas distendidas con los ex presidentes George HW Bush y Bill Clinton cuando eran candidatos en 1980 y 1991 respectivamente; el uso de metáforas según los Estudios del Discurso Crítico de la Lingüística Cognitiva; el estilo lingüístico de los mítines de Donald Trump en las elecciones de 2016; y la negociación de la victimización de los solicitantes de asilo en las organizaciones que trabajan por los derechos de los refugiados.

\section{Discourse, Context \& Media (Inglaterra, Elsevier) Volumen 23, 2018}

Esta edición contiene un monográfico que se centra en diversas facetas de la sociolingüística de la ficción en el cine, las series de televisión, la publicidad, la literatura y la música. En concreto, los artículos incluidos tratan los estereotipos de los personajes de Asia del Este en la saga de James Bond; las parodias de actores blancos pintados de negro en el género del minstrel o bufón, que aunaba la ópera inglesa con la música negra de las plantaciones del sur de Estados Unidos; y la identidad feminista global de Mona AKA Sad Girl, una rapera japonesa que canta en japonés, inglés y español. Este monográfico también trata las ideologías lingüísticas presentes en la lengua criolla de Hawai conocida como pidgin, el poder del humor en una campaña antirracista en YouTube, una aproximación sociopragmática al diálogo de los personajes neandertales en la obra de William Golding, la construcción de la pobreza elegante de las clases altas en la literatura griega femenina, y la intersección de los campos del Análisis Crítico del Discurso y de la Ideología del Lenguaje.

49. Interaction Studies (Países Bajos, John Benjamins Publishing) Volumen 18 (3) 2017

Este ejemplar dispone de estudios sobre la interacción y la iconicidad en la evolución del lenguaje, un modelo teórico para explicar los sistemas de la comunicación humana, un enfoque empírico para explorar los orígenes de la estructura en el discurso, el proceso de convencionalismo y discriminación en las señales auditivas continuas, la evolución cultural de las propiedades estructurales del lenguaje, y la multimodalidad gestual, visual, vocal y auditiva en la evolución del lenguaje. 


\section{Convergence: The International Journal of Research into New Media Techno- logies (EE.UU., SAGE) Volumen 24 (2) 2018}

En esta edición el lector tiene acceso a investigaciones que abarcan la emergencia de nuevos escritores en plataformas digitales de autopublicación como Wattpad, el comportamiento de las audiencias frente a los finales destripados (spoilers) en la era de la post-televisión, la conversión online del canal 3 de la BBC y su transición a servicios de descarga y a emisiones en directo online (streaming), la escasez de estudios sobre la comunicación política en los medios digitales, la explotación de los fans en la serie de YouTube Lonelygirl15, y la relación de la identidad digital con la gobernanza mundial de Internet.

\section{Communications-European Journal of Communication Research (Alemania, De Gruyter Mouton) Volumen 43 (1) 2018}

En este ejemplar los expertos abordan en varios artículos la incidencia de los medios y de la opinión pública en las fluctuaciones del mercado de valores; la influencia de la empresa propietaria de un medio en su cobertura informativa de los partidos políticos; el efecto de las relaciones sociales y del tipo de tema en la selección de un medio de comunicación por parte de la audiencia; la importancia de la exposición a los medios y de los propios prejuicios en el debate sobre los refugiados entre diferentes segmentos de la población alemana; la perspectiva de los periodistas belgas respecto al uso de la opinión de la calle (vox pops) en radio y televisión; y el consumo mediático de los refugiados sirios en Turquía.

\section{Critical Discourse Studies (Inglaterra, Taylor \& Francis) Volumen 15 (3) 2018}

Este número difunde varios trabajos que exploran el análisis de la argumentación en base a consideraciones transdisciplinarias del análisis crítico del discurso, la economía política y el materialismo histórico; las estrategias argumentales utilizadas por gobierno y oposición para culparse mutuamente de la crisis financiera en el Reino Unido; así como la diseminación del neoliberalismo tanto en los textos para la enseñanza del inglés en academias privadas en Irán, como en la cobertura informativa de las violaciones, que enfatiza las nociones de victimización y riesgo y favorece los intereses de los agresores. Los últimos artículos estudian el discurso del gobierno polaco en base al miedo y la amenaza que supone la inmigración para justificar medidas preventivas contra los inmigrantes; y los vídeos en YouTube del teleevangelista musulmán estadounidense Baba Ali.

53. Critical Studies in Media Communication (EE.UU., Taylor \& Francis) Volumen 35 (2) 2018

Las investigaciones de esta edición analizan la reconceptualización de la mirada, porque sitúa a la atención como la mercancía más valorada y como agente que influye en 
el comportamiento social y económico del público; el marketing guiado por los datos como forma de control del comportamiento del consumidor; la retórica sexista y homofóbica de la serie estadounidense Scream Queens, concebida en un principio para contrarrestar esa misma retórica; la mercantilización de la homosexualidad afroamericana, la masculinidad y la sexualidad en la serie Love \& Hip-Hop; la construcción del feminismo milenial en la serie animada Bob’s Burgers; y la subordinación de la línea informativa de Sky News al gobierno de Qatar, sobre todo en las acusaciones de terrorismo, debido el patrocinio comercial de la cadena por parte de la línea aérea estatal Qatar Airways.

\section{Discourse Studies (Inglaterra, SAGE) Volumen 20 (3) 2018}

Los trabajos de este número exploran diferentes aspectos en el estudio del discurso. En concreto, los artículos expuestos abordan el papel de la risa como terapia cognitiva y del comportamiento, la respuesta de la hermana mayor a los retos verbales de la hermana menor, el lenguaje no verbal del discurso en estilo indirecto, el progreso de la terapia en forma de sesión radiofónica, el estudio científico de la conversación como objeto informativo, y la conexión del análisis de la conversación con la etnometodología.

\section{Language \& Communication (Inglaterra, Elsevier) Volumen 60 (2018)}

Los temas escogidos para los artículos de este número abarcan el discurso periodístico sobre los riesgos a la salud causados por la contaminación del aire en China, las letras de seis artistas del género de música electrónica conocido como grime en el Reino Unido, la calidad de los servicios de interpretación y traducción para los refugiados en España, y las ideologías lingüísticas respecto a las diferencias entre gesto y signo. Otros textos estudian las representaciones visuales publicitarias de la comunidad china en Hong Kong, la ambigüedad en las narrativas sobre la inclusión o exclusión de la comunidad gay, bisexual y transexual (LGTB) en iglesias cristianas, las identidades lingüísticas bilingües en la música popular tejana, el discurso de los partidos políticos griegos New Democracy y Syriza en los anuncios electorales de los comicios griegos de 2015, y las prácticas discursivas de los usuarios “ordinarios" de redes sociales.

56. International Journal of Conflict Management (Inglaterra, Emerald) Volumen 29 (3) 2018

Los ejes de este ejemplar giran alrededor de los diferentes modos de gestionar los conflictos, sobre todo los laborales. Para mostrarlos, se presentan artículos sobre la gestión de problemas en empresas con jóvenes profesionales chinos, que son cada vez más turbulentas por la etapa de transición que vive el país; la interrelación entre líderes y miembros de un equipo de trabajo para gestionar el efecto del conflicto 
emocional en un comportamiento innovador; la implementación de la gestión de residuos en China en base al modelo bayesiano de inferencia estadística; la influencia de las variables personales en una negociación partiendo de la teoría de la sincronicidad mediática; y la huella del liderazgo emocional en el trabajo en equipo.

57. Communication and Critical-Cultural Studies (EE.UU., Taylor \& Francis) Volumen 15 (2) 2018

En este número el lector dispone de trabajos que divulgan una crítica de la postverdad a partir de la ideología y no de la epistemología, la creación de comunidades de apoyo para la reinserción de mujeres encarceladas, un estudio de los voluntarios estadounidenses en una ONG en Tanzania, la victimización de la masculinidad en la película Foxcatcher, y el grafiti como ruptura estética y lengua vernácula.

58. Personal Relationships (EE.UU., Wiley-Blackwell Publishing) Volumen 25 (1) 2018

Este ejemplar examina los factores contextuales, relacionales y personales en la comunicación del perdón tras un problema de pareja, la depresión y los problemas de relación entre las mujeres recién casadas, la importancia de la claridad en la comunicación de los sentimientos en la dinámica de pareja, el papel positivo de la autoestima en la resolución de problemas maritales, y el juicio moral hacia las traiciones e infidelidades en la pareja. También se trata la dificultad en las relaciones entre hijos adultos y padres envejecientes; el uso de una aplicación informática para establecer los modelos de interdependencia en la pareja; los efectos psicopatológicos de los conflictos interparentales y de la actitud intrusiva de los padres en los hijos en edad universitaria; y los mecanismos relacionales en la consecución de objetivos.

\section{Argumentation (Países Bajos, Springer) Volumen 32 (2) 2018}

En esta edición se exploran varios elementos relacionados con la argumentación, como el discurso responsable y fiable de los virtuosos, la persistencia del prejuicio en las opiniones de los expertos, los argumentos utilizados en los litigios judiciales, la evaluación de los razonamientos en función de la situación epistémica del evaluador, y las explicaciones en temas de salud con el método Cochrane de revisión sistemática.

\section{Visual Communication (EE.UU., SAGE) Volumen 17 (2) 2018}

Las investigaciones tratadas en este número estudian la visualización de la línea ideológica de un periódico en su diseño, el enfoque Semiótico Social Multimodal en el estudio de los gráficos, una aproximación multimodal a la moda femenina en Oriente Medio, la taxonomía visual de los fotomapas, la interpretación de los espectadores de 
los movimientos laterales de la imagen en el cine, y el vídeo vertical y su ruptura con el paradigma estético.

\section{The Translator (Inglaterra, Taylor \& Francis) Volumen 24 (1) 2018}

Este ejemplar se enfoca en artículos sobre la correspondencia de la portada de un libro con los textos traducidos, las traducciones de las variedades lingüísticas en los subtitulados de los productos audiovisuales, la intervención de los editores en la traducción de las nominalizaciones de inglés a alemán, las normas de traducción en inglés de los textos culinarios, las dificultades en las traducciones de derecho laboral comparado en un mercado global, y los retos que enfrenta la profesión del traductor en Irán.

62. Asian Journal of Communication (Inglaterra, Taylor \& Francis) Volumen 28 (3) 2018

Este número propone a sus lectores textos acerca de los seguidores en Twitter de los parlamentarios de Corea del Sur, la combinación del mensaje con la personalidad del usuario en la efectividad de la publicidad electoral, la mediación del discurso político en la movilización de los votantes dentro y fuera de Internet en función de su ideología, la percepción de la opinión pública china sobre la contaminación atmosférica, la comunicación entre doctor y paciente como factor de mejora de la salud emocional en China, y la adaptación de un modelo intercultural para la comunicación entre instituciones y minorías étnicas.

\section{International Communication Gazette (EE.UU., SAGE) Volumen 80 (4) 2018}

Esta edición recoge un especial sobre el constitucionalismo digital y los derechos y límites al poder en el ecosistema de Internet. En relación al constitucionalismo digital, los temas tratados en el especial son el diseño de una Carta de Derechos de Internet, con hincapié en los derechos humanos; el papel de los parlamentos nacionales en este tema; el intento de creación por parte de la UNESCO de un marco internacional para el acceso universal a Internet; el desequilibrio entre privacidad y seguridad en la política de telecomunicaciones y ciberseguridad en Australia; y la necesidad de regular la gobernanza de las redes sociales y los intermediarios en el mercado de las telecomunicaciones.

64. Chinese Journal of Communication (Inglaterra, Taylor \& Francis) Volumen 11 (1) 2018

La presente edición está centrada en un monográfico que trata las tendencias en las relaciones públicas y la comunicación estratégica en la era digital en China. Las in- 
vestigaciones incluidas examinan las diferencias en la gestión de la comunicación de crisis en las empresas públicas y privadas en China, las donaciones de los milenials chinos a organizaciones caritativas a través de la red social móvil WeChat, y el rol de las firmas de relaciones públicas en China y Estados Unidos en la medición de predictores de confianza demográficos, económicos y políticos. Otros estudios abordan la incidencia de los medios estatales chinos en la agenda de la cobertura informativa en Singapur y Taiwán de las protestas de Hong Kong de 2014; y la contribución de los medios a la confianza de la opinión pública en las acciones de los gobiernos locales respecto a los riesgos medioambientales en China.

\section{Social Semiotics (Inglaterra, Taylor \& Francis) Volumen 28 (3) 2018}

El contenido de este número gira en torno a la resemantización de la representación discursiva del presidente sudafricano Jacob Zuma, la sexualización de la paternidad, la arquitectura estructuralista del socialismo en la antigua Yugoslavia, la rebelión cultural y semiótica de las mujeres roqueras chinas contra el rock dominado por los hombres a finales de los años 90, la distorsión de las estadísticas sobre la demencia en la prensa británica en 2016, el discurso contemporáneo de la pobreza en India, la iconicidad y los símbolos en la construcción de una imagen de marca, y la ansiedad del amor reflejada en la música china contemporánea.

66. Continuum-Journal of Media \& Cultural Studies (Inglaterra, Taylor \& Francis) Volumen 32 (3) 2018

Las dinámicas transnacionales en las prácticas culturales en Australia dan título al monográfico de esta edición, que cuenta con varios artículos acerca de la herencia cultural de Australia, el nivel de lectura de la población, el consumo de productos culturales étnicos, y los gustos culturales de los aborígenes. Por otro lado, los artículos de investigación fuera del monográfico se dedican a la representación de las campañas a favor o en contra de las ballenas en la prensa australiana y japonesa, la mediación de las pantallas móviles en la celebración del día nacional de Australia, la integración del feminismo en los blogs de moda adolescente femenina, los imaginarios transnacionales de Hollywood desde Indiana Jones hasta World War Z, la resistencia feminista en la estructura de matriz de la serie The Real Housewives, y la conmemoración del trauma en los monumentos públicos.

67. Quarterly Journal of Speech (Inglaterra, Taylor \& Francis) Volumen 104 (2) 2018

Entre los artículos a disposición del lector en este número hay una redefinición de la violación a través de la contrapublicidad visceral, el legado de Booker T. Washington a favor de los derechos de los afroamericanos estadounidenses a mediados del siglo XIX, la retórica emocional y afectiva del ex presidente Barack Obama en su discurso 
tras un tiroteo mortal en Arizona en 2011, y la retórica simbólica de Jacques Lacan aplicada al votante de Donald Trump en 2016.

\section{Journal of Mass Media Ethics (EE.UU., SAGE) Volumen 33 (2) 2018}

Los estudios que examina esta edición abordan el fracaso de la formación ética de los periodistas en Camboya, la cobertura informativa de la responsabilidad social corporativa en el periódico de finanzas español Expansión, y la promoción de la conservación del medioambiente en la obra periodística de Thomas French.

\section{Javnost-The Public (Inglaterra, Taylor \& Francis) Volumen 25 (1-2) 2018}

Bajo el título de "La liquidación de lo Público: Comunicación, Democracia y la Esfera Pública en la Era de Internet", el monográfico de esta edición contiene una treintena de investigaciones al respecto. Entre los temas del monográfico destacan la crisis epistémica de la democracia por las nuevas formas de conocimiento derivadas de las tecnologías digitales, los límites de la teoría de la esfera pública y la destrucción de la democracia deliberativa, y la recuperación de la teoría de Habermas sobre los ciudadanos como sujetos de la refeudalización de la esfera pública. El potencial de la juventud árabe para equilibrar el espacio virtual y promover la cultura cívica en la región, la crisis de la comunicación pública desde 1995 por la digitalización e Internet, y el papel de la esfera digital en las movilizaciones políticas en España e Italia desde el año 2000 también centran el monográfico. Los artículos fuera del especial muestran la doble hermenéutica de la investigación en comunicación, una perspectiva crítica del mundo post-Internet, la economía política de la comunicación en el siglo XXI, y los nexos entre la desigualdad de género en los medios y las políticas mediáticas.

70. Communication, Culture \& Critique (Inglaterra, Taylor \& Francis) Volumen 10 (4) 2017

Los trabajos divulgados en este ejemplar se centran en el resurgimiento de los fanzines feministas en Estados Unidos, la lucha por la libertad de expresión de los usuarios de redes sociales en Turquía, las estrategias de mercadotecnia del opio como analgésico para extender la base de sus consumidores, el empoderamiento de las jóvenes afrobrasileñas en los medios alternativos de Brasil, y la demanda de las audiencias del Reino Unido y Alemania para regular los contenidos ofensivos en televisión. Este número también dispone de investigaciones sobre el multiculturalismo representado por Jasmine Lee, la primera filipina nacionalizada como surcoreana; el activismo de las radios comunitarias del norte de Senegal a favor del pulaar, una lengua hablada por una minoría de senegaleses y mauritanos; el significado del heroísmo y de los símbolos religiosos en los medios chiitas de Irak; la superioridad y los estereotipos de Corea del Sur en el blog Eat Your Kimchi; el reconocimiento 
transnacional del actor argentino Ricardo Darín; y la música tradicional como medio de resistencia de la minoría Hazara de Afganistán.

71. Media International Australia (Australia, Univ Queensland Press) Volumen 167 (1) 2018

Los textos que expone este número divulgan la importancia de la Galería de Prensa de Canberra como institución periodística; el surgimiento de un nuevo liderazgo de la audiencia al calor de los medios digitales; las semejanzas y diferencias de los sistemas políticos y mediáticos en Australia y el Reino Unido; y la desintegración del rol intermediario del periodista ante el uso de las redes sociales por los políticos, como el ex primer ministro John Howard (1996-2007), para comunicarse directamente con el público. El resto de artículos cubre las relaciones entre la prensa parlamentaria y la primera ministra Julia Gillard durante el conflicto en Afganistán (2010-2013); la influencia de los cambios políticos en el uso de las redes sociales, en concreto Twitter, por parte del primer ministro australiano Malcolm Turnbull; la construcción de la identidad periodística de rueda de prensa en el periódico Guardian Australia; la teoría del capital cultural en la Australia contemporánea; y las nuevas tendencias de la televisión en el país.

72. Narrative Inquiry (Países Bajos, John Benjamins Publishing) Volumen 27 (2) 2017

Las investigaciones disponibles en esta edición cubren las reseñas de productos de Amazon escritas en forma de parodia, la transformación de las historias tras su viralización en las redes sociales, las prácticas narrativas en Facebook de la diáspora portuguesa en Francia, el storytelling colaborativo entre adolescentes como instrumento contra el acoso escolar, y la construcción de narrativas e identidad en aulas multiculturales en Italia.

73. Tijdschrift voor Communicatiewetenschap (Países Bajos, Uitgeverij Boom Bv) Volumen 46 (1) 2018

Esta revista es la única publicada en lengua holandesa en esta edición del JCR, y presenta cinco artículos que tratan las posibilidades del análisis de texto automatizado en lengua holandesa; las técnicas de recogida del contenido digital; la utilización de métodos etnográficos enriquecidos con datos de comportamiento para rastrear las huellas digitales del consumo informativo; el estudio de los programas de televisión en Holanda en base al formato y no al género; y la reconstrucción de los encuadres culturales utilizados en las noticias, las redacciones, y las mentes de los periodistas. 
74. Journal of African Media Studies (Inglaterra, Intellect LTD) Volumen 9 (3) 2017

Este número recoge investigaciones que difunden el resultado de las iniciativas mediáticas que surgieron en Sudáfrica tras el fin del apartheid, el intento de transformación de la enseñanza del periodismo en Sudáfrica para alejarlo de la occidentalización, un modelo relacional de los programas de entrevistas (talk shows) en la lengua Ubuntu, la representación de las relaciones entre África y China en los medios africanos, el apoyo de las celebridades a las campañas políticas en Nigeria y la respuesta de los estudiantes universitarios al respecto, el teatro como medio alternativo en Zimbabwe, la creación de mitos políticos en las políticas mediáticas de Sudáfrica, y el papel de los medios como actores políticos en este país. 